\title{
Policy issues related to the governance of local service boards in Northern Ontario
}

\author{
Denis J. Rochon
}

\begin{abstract}
More than half of residents in Northern Ontario are living in unincorporated communities where there is no country-level system of government. Local service boards (LSB) have been contracted by the Government of Ontario to provide municipal-level services, however residents are faced with increasing challenges as the current legislative framework is failing. Recent impediments to new provincial regulations for water and waste water management, increasing costs of energy and solid waste disposal, higher insurance and audit costs and a declining population are threatening the sustainability of the communities that already suffering from ongoing social and economic issues. This paper provides a detailed map of LSBs, presents the common issues facing the communities, and offers policy recommendations to help redress the situation.
\end{abstract}

Keywords: Northern Ontario, local service boards (LSB), municipal-level service, sustainability.

\section{Prologue}

Foleyet, a small community 110 kilometres west of the City of Timmins, in Northern Ontario's unincorporated territory, has 300 permanent residents. It is headed by a Local Services Board with the mandate to deliver a total of six services, the most significant of which is the management of a communal 7drinking water plant and distribution system.

In 2006, the community hired the services of the engineering firm Tottem Sims Hubicki Associates to assess the state of the water plant, identify areas of concern, and propose mitigating measures along with associated costs. The news was not good. The needed plant upgrades would cost them $\$ 325,000$.

In order to fully illustrate the extent of the problem, the more disturbing issues identified in the Totten Sims Hubicki Associates study are summarized as follows:

\section{High and Low Lift Pumps Overhaul}

Although most of the electrical equipment was replaced after flooding in 1996, the high and low lifts pumps remained. They have been in operation for approximately 19 of their 20 -year design lifetime. 


\section{Plant Water Quality Monitoring and Recording Instruments}

The Endress and Hauser paper chart recorder tracks raw and treated water flow, turbidity and chlorine residual. Costs and climate-controlled storage for the inks and paper are problematic. The filtered water turbidity analyzer continuously records turbidity in the filter water discharge, even when the filter is shut down. This has caused difficulties when the filter is shut down since high turbidity spikes are recorded when the filter is not operating.

\section{Standby Diesel Generator Overhaul}

The plant has a $36 \mathrm{~kW}$ standby diesel generator set. The diesel generator set has the following issues:
a. Starter needs repair;
b. One of the injectors is showing signs of malfunctioning;
c. The generator set is water cooled and when it is initially started there is no high lift pressure to supply water to the unit; and
d. The generator requires general servicing.

\section{High Lift Pump Check Valves}

The check valves for the high lift pumps are $75 \mathrm{~mm}$ plumbing style swing check valves with threaded connections. These check valves are difficult to maintain and are likely worn out.

\section{Alum Tank}

Alum Tank No. 2 is cracked.

\section{Water Treatment Plant Roof}

The roof of the water treatment plant building is steel and there is no protection from ice and show sliding off the building over the main entrance door. This can be an operator safety issue in that falling snow and ice could injure staff.

\section{Plant Chemical Storage Area}

There is no adequate heated area within the plant for storage of sodium hypochlorite solution. An un-insulated building is used for storage of polymer and soda ash chemicals. The Ministry of the Environment has directed that plant staff should not store sodium hypochlorite in this area.

\section{Office and Laboratory Area}

The office area for the plant consists of a single desk in front of the main entrance door. This area is also used as the plant laboratory. The laboratory and records storage spaces are very restricted and this impairs the plant staff's ability to operate the plant effectively.

\section{Plant Flooding}


The Foleyet Water Treatment Plant road leads downhill toward the Ivanhoe River. Because of the plant's proximity to the river, a flood protection berm was built between the plant and the river. However surface runoff flows down the road, pooling behind the berm. The plant site's grade causes runoff to enter the building, where it runs through floor drains to the river. In 1996, metre-high flood waters entered the plant, causing damage to electrical equipment, necessitating its replacement. A similar event occurred again in 2003, prompting a boil water advisory in the community. Flood damage has occurred to the plant's structure as well. Flooding at the plant could potentially result in severe cases of contamination of the raw water well and/or clear well (Totten Sims Hubicki Associates, 2005).

How could such a vital part of the community's infrastructure have degenerated to this extent? Where were the necessary funds to operate, maintain and upgrade the equipment? What environmental factors hastened the plant's decline? What led to this situation where any attempts at refurbishment are inadequate and lag behind the process of deterioration?

The community's water plant was built in 1988. For the first 15 years of operation, the water plant was run by volunteers, none of whom had the required certification to operate such a system. The plant quickly fell into disrepair, as much of the needed preventative maintenance and upkeep was not regularly or professionally undertaken.

The Local Services Board (LSB) was ill-equipped to deal with the responsibilities and legal requirements for the operation of a communal drinking water system. This, along with the community's limited financial capacity to manage the system maintenance and repairs properly, has contributed to creating an ideal environment for failure.

In 2006, the community's total tax base was estimated at $\$ 112,700$. The balance was covered through the Ministry of Northern Development and Mines annual operating grant, rental of the LSB's office space and community hall, and community fundraising activities. The number of permanent residents has been in steady decline since the 1991 census. The service charges levied on the residents increased by 220 per cent in the last three years, simply to keep up with the rising operating costs of the LSB. In 2005, the LSB sold one of its properties in order to raise the necessary funds for an eventual water plant upgrades project, should provincial and federal funding be made available. To date, the LSB remains unsuccessful in accessing any such financial support.

Some repairs to the water plant were undertaken in 2004 through a $\$ 320,000$ project, funded for the most part by the Ontario SuperBuild Corporation's Ontario Small Town and Rural Development Initiative. Repairs worth twice that amount would have been necessary to bring the plant up to standard and make it properly functioning. 
A number of underlying issues have served as precursor and contributor to the current situation. The Foleyet state of affairs is not unique among LSBs throughout Northern Ontario. What are the causes of such disquieting conditions? Are LSBs negligent in the administration of essential services for their communities, or is the context in which LSBs operate condemning them to sink? Is a human tragedy necessary to attract the needed attention to pressing issues faced by communities such as Foleyet? Let us examine how predicaments such as Foleyet's have emerged over the years.

\section{Introduction}

Northern Ontario offers interesting challenges to its governing bodies, with its vast and resourcerich territory and relatively scattered and sparse population. While formal structures and relationships exist between the provincial and municipal governments, and between First Nation communities and the federal government, managing programs and servicing populations in the areas outside of municipal or First Nation jurisdictions in Northern Ontario can be perplexing.

The Northern Ontario land mass commonly known as the unorganized territories, outside of municipal and First Nation jurisdictions, is approximately 730,000 square kilometres and inhabited by 41,000 permanent residents. Roughly 26,000 are living within unincorporated communities called Local Services Boards. Another estimated 14,000 seasonal residents also have properties within those Local Services Board areas (Statistics Canada, 2001).

The LSBs were created under the Local Services Boards Act (LSBA) to facilitate the delivery of nine basic community services in unincorporated areas of Northern Ontario. Passed into law in 1979, the LSBA was administered by the Ontario Ministry of Northern Affairs. ${ }^{1}$

Although the LSBA was a laudable solution in addressing the urgent need for a service delivery mechanism in unincorporated areas, it has become somewhat debilitating for communities amid ongoing social, economic and regulatory changes. More specifically, LSBs increasingly face encroaching elements that may render their sustainability questionable. This situation is further amplified by a legislative framework governing them that was not thoroughly updated or revised to reflect the changing environment. Some of the more significant and recent impediments include new provincial regulations for water and waste water management, increasing costs of energy and solid waste disposal, higher insurance and audit costs, and a declining population.

As a vessel's seaworthiness is determined by the sturdiness of its hull, the upkeep of its equipment and the competence of its crew, so is a policy's effectiveness determined by the suitability of its composition, the adaptability of its programs and the preparedness of its

\footnotetext{
${ }^{1}$ Northern Services Boards Act, R.S.O. 1990, c. L. 28, Laws, Province of Ontario (Section 1)
} 
stakeholders.

This paper will attempt to draw a detailed map of LSBs, present the common issues that contribute to their malaise, and offer some insights into some of the more problematic elements in the governance of the unorganized areas of Northern Ontario as impacted by the NSBA given the current context. As a final note, the paper will offer a series of policy recommendations to help redress the situation without undermining the original intent and purpose of the LSB section of the Northern Services Boards Act.

\section{Time capsule: Creation of a life raft}

In the 1970s, communities in the unorganized areas of Northern Ontario were increasingly demanding essential services from the provincial government. On an annual basis, forest fires threatened communities incapable of responding because of the absence of an organized fire response team. Other serious incidents causing death also occurred, accentuating the need for fire protection in the smaller remote communities. Those in the unorganized areas had no form of municipal structure and generally were remote from municipalities with fire-fighting capabilities.

In 1978, the Ministry of Northern Affairs launched a pilot program to train and equip volunteer firefighters in small remote communities. The communities organized fire protection teams under the Ontario Solicitor General's guide, while Northern Affairs paid for the Workers' Compensation Board (WCB) coverage. The Ontario Fire Marshall was responsible for the training, and Northern Affairs paid for the fire prevention school travel and meal costs. Northern Affairs also provided funding for portable firefighting packages through its Isolated Community Assistance Fund, a special program aimed at providing essential services to unorganized remote communities in Northern Ontario.

As the fire teams were formed and trained, the issue regarding operating costs for these teams or departments became apparent. If the province was to entertain operating funding, the transfer of funds from the province to the communities also needed attention. Since most of the volunteer fire teams were not established as corporations, the province needed to find a mechanism that would allow the transfer of funds without sacrificing the requirement for accountability and transparency. The fire team idea also became the catalyst for communities looking for the delivery of other essential services to their inhabitants.

In 1979, a solution was proposed by a concerned resident of Gogama, a small community of 800 inhabitants located 200 kilometres south of Timmins. Using the Local Roads Board Act as a template, a draft concept of a Local Services Boards Act was introduced to the then Minister of Northern Affairs. The main purpose of this Act was to facilitate the delivery of basic community 
services in unincorporated areas of Northern Ontario.

Following a series of community consultations, and after careful reworking of the original proposal by Northern Affairs policy staff, a final version of the Local Services Board Act (LSBA) was passed in the Ontario Legislature by year's end in 1979. Fairly simple and straightforward in its wording and workings, the LSBA, by order of the Minister of Northern Affairs, authorized the establishment of Local Services Boards, determining their boundaries, their board composition, and the scope of powers they could exercise; all according to the requests made by the respective communities.

The LSBA was considered a veritable life raft for remote communities too often left drifting on stormy waters, ill equipped to fend for themselves against adversities. It also provided communities with new tools and the means to better meet the needs of their inhabitants through the delivery of some basic essential services.

In 1990 the LSBA was revised as part of a Province-wide exercise to consolidate its statutes and regulations. This came into force as part of the Revised Statutes of Ontario, 1990, which were proclaimed in force on December 31, 1991. No fundamental changes were made to the LSBA, although a number of regulations that sprang from it were melded into the Act... a housekeeping exercise.

\section{Defining local services boards}

Local Services Boards would be established as corporations, although the Corporations Act of Ontario would not apply to the Boards. Communities would elect a Board comprised of three or five members. The size of the community would in most cases be the determining factor for the size of its Board. LSBs would not operate as a municipality nor would they be compared to such.

The Boards would be given the authority to exercise up to six powers through which basic services were to be provided: water supply, fire protection, garbage collection, sewage, street or area lighting, and recreation. The choice of powers to be exercised would be made by the respective communities. The services under those powers would be delivered solely within the confines of established boundaries for a community.

The LSBA also provided the Board with the authority under the Provincial Land Tax Act to impose a levy or service charges, and "make all arrangements necessary to provide, maintain and improve services in the Board area". 2 This authority to impose rates was considered an essential element to ensure the financial viability of the Boards. The life raft would need oars, after all.

\footnotetext{
${ }^{2}$ Local Services Board Act, R.S.O. 1980, c. 252 L. 28 - Section 7 (1), Laws, Province of Ontario
} 
The communities could get matching funding for operating costs through a special fund created and administered by Northern Affairs specifically to support LSBs. As for capital projects, Northern Affairs established a capital funding program, The Unincorporated Community Capital Assistance Program, through which communities could apply for 75 per cent funding to be used toward eligible projects.

There were 63 LSBs in the 1990s. By 2007, this number had been reduced to 46 through annexations to municipalities and dissolutions. The map below shows the latest number and locations of LSBs dispersed throughout the unorganized territory of Northern Ontario.

\section{Figure 1: LSB sites in Northern Ontario}

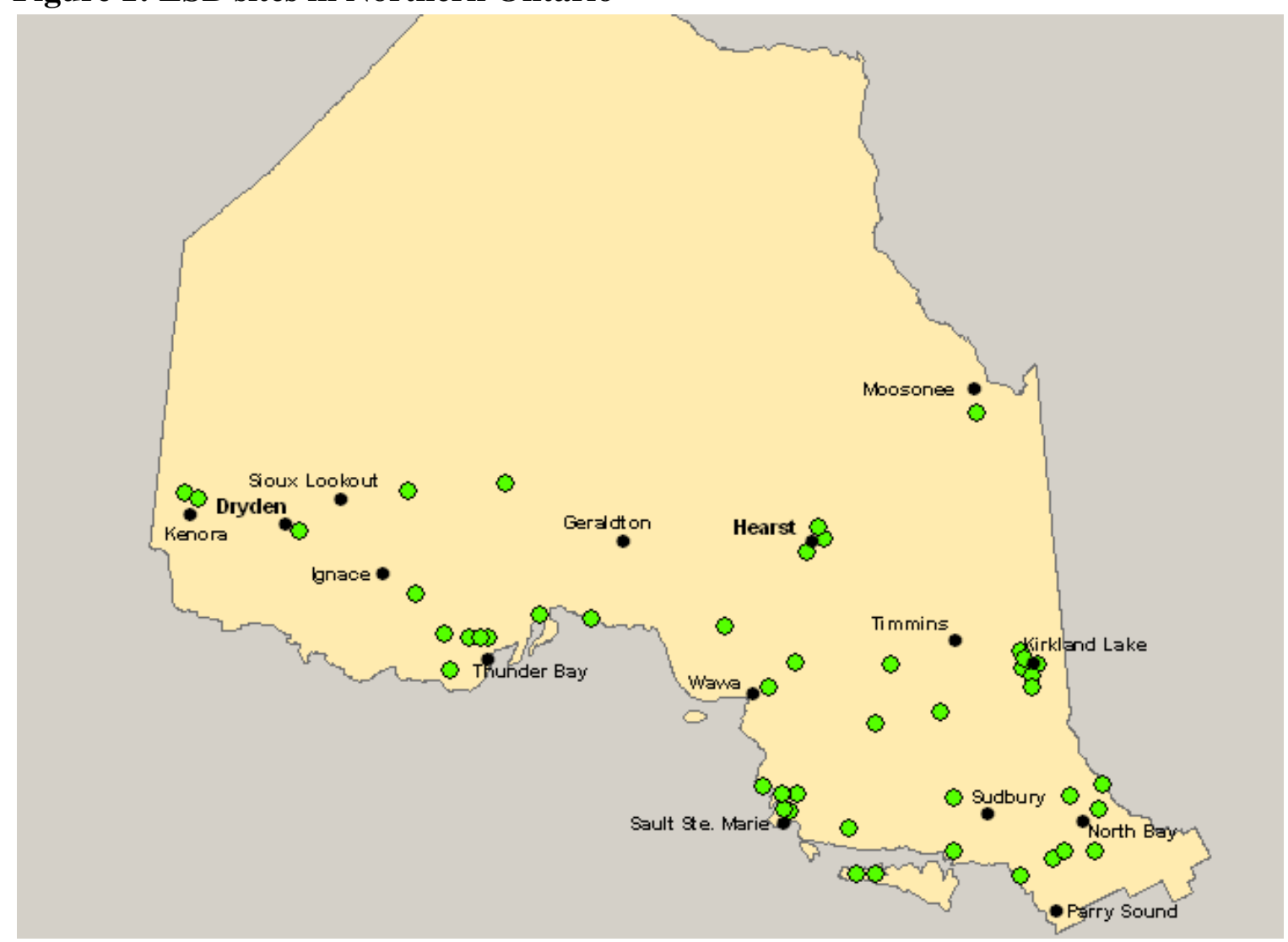

Source: Ministry of Northern Development and Mines. (2007). LSB sites.

\section{The changing waters}

In January 1997, the Government of Ontario announced sweeping reforms of the provincialmunicipal relationship. This reform process took in excess of four years from start to finish. The Ministry of Municipal Affairs and Housing, in partnership with the Association of Municipalities of Ontario, helped lead the process with the publication of Who Does What: Toward Implementation in 1998, designed to provide a comprehensive overview of Local Services Realignment reforms and to assist with implementation. 
Municipalities were asked to develop plans to consolidate management of social and community health services for approximately fifty municipalities and Northern services boards. They were given a document called Two Consolidated Planning Frameworks: one for the North and one for the South. The province wanted northern municipalities to consider Service Managers that could assume responsibility for the management of social assistance, child care, social housing and possibly land ambulance and public health.

In the background, the Ministry of Northern Development and Mines (formerly Northern Affairs) formed the Northern Services Implementation Project to work on Local Services Realignment initiatives. Consultations were held throughout Northern Ontario in an attempt to find formulas that corresponded with the socio-political character of the region.

The discussions centered on how to improve local services delivery options in the North with the aim of developing more efficient and cost effective government in Ontario. Two models were proposed: District Social Services Administration Boards (DSSAB) and Area Services Boards (ASB).

DSSABs would play the role of municipal delivery agent, taking on responsibility for managing the delivery of most social and community health services in Ontario, such as the Ontario Disability Support Program, Ontario Works, land ambulance service, and senior and low-income housing.

ASBs would be single service delivery agencies on an area-wide basis that could potentially be comprised of municipalities, Local Services Boards, Local Roads Boards, and the unorganized areas outside of their respective boundaries.

While the Ministry of Community and Social Services took responsibility for District Social Services Administration Boards, the Ministry of Northern Development and Mines (MNDM) led the way for Area Services Boards.

\section{Birth of the Northern Service Boards Act}

A plan was in place to bring the LSBA and the concept of ASBs under one umbrella. While the Local Services Realignment exercise examined how to combine Local Roads Boards with Local Services Boards, as well as include additional powers for LSBs, a Northern Services Implementation Project Inter-Ministry Committee was established to develop the legislative framework and implementation protocols for Area Services Boards.

On April 1, 1999, the LSBA evolved into the Northern Services Boards Act (NSBA) (Association of Municipalities of Ontario, 1999). Two new powers were added to the six in 
place under the LSBA: the power of Public Library Services and the power of Roads. The NSBA was divided into two parts: Part One pertained to Locals Services Boards, and Part Two was on ASBs.

At the same time, ten DSSABs and the Region of Sudbury were established by regulations under the District Social Services Administration Boards Act and the Ontario Works Act. While DSSABs became workable entities under the law, Area Services Boards were deemed not seaworthy even though half of the NSBA dealt with the establishment and operations of ASBs.

Notwithstanding the fact that the ASB model would address the need (expressed by Northerners) for a more regional approach to the administration and delivery of essential services to the unincorporated communities, its greatest challenges, that made it impossible to implement, were the absence of a workable assessment mechanism for properties in the unorganized territory and the deficiency of accurate and comprehensive census data on its permanent and seasonal inhabitants.

There is no functional and practical method of revenue collection for ASBs, predicated on the "inability to have current value assessment for all properties within the boundaries of an unorganized area to calculate the revenue share by weighted assessment” (Jensen, 2000).

This situation is further complicated by the lack of sufficient population data in the unorganized territory. This renders the delivery of specific essential services impractical, as the determination of appropriate levels of service would not necessarily be based on accurate and complete demographical information.

There is however a glimmer of hope for ASBs. The Ontario Government passed legislation in 2006 to implement a current value property assessment system in the province's unincorporated territory. The updated assessments are to take effect in 2009.

Also, the current policy directions in the province are shifting to better work through priority issues related to service delivery. The Provincial-Municipal Fiscal and Service Delivery Review is underway in 2007 to consider options regarding service system delivery, capacity, and governance arrangements. Although this exercise involves the intergovernmental cooperation between the province and municipalities, it may as a consequence necessitate a more focused look at governance in the unincorporated areas in the near future.

The woes of ASBs is a topic unto itself that could be treated in a separate study. For the purpose of this paper, a short introduction on the issues related to the implementation of ASBs serves to demonstrate some of the intricacies of developing policies pertinent to and applicable in the unorganized territory of Northern Ontario. 


\section{A plan on a lee shore: Legislative restrictions and shortfalls}

The process of creating legislation is by its very nature a laborious undertaking, in consideration of the repercussions on province-stakeholder relations, the fiscal and legal requirements, and the impact on other Ministries and existing legislation when drafting regulations.

Defining the term "policy" can be in itself a challenging enterprise. The Webster's New Collegiate Dictionary provides the following: "a definite course or method of action selected from among alternatives and in light of given conditions to guide and determine present and future decisions; a high-level overall plan embracing the general goals and acceptable procedures especially of a governmental body" (Webster's New Collegiate Dictionary, 1997).

Leslie A. Pal, author of Beyond Policy Analysis - Public Issue Management in Turbulent Times, defined public policy as "a course of action or inaction chosen by public authorities to address a given problem or interrelated set of problems...They are actualized through an implementation process that elaborates programs and activities to give the policy effect" (Webster's New Collegiate Dictionary, 1997).

In a perfect world, necessity would be the main driver in the decision to introduce new policies. Unfortunately, policies are also spawned from a variety of interests and at times conflicting realities, where the choice of direction and degree of consideration can be swayed by the level of political appetite of the day in dealing with a problem.

Ideally, a policy is permeated with wording or structure that encourages a flexible approach, or is revisited and adjusted periodically to allow for better maneuvering among changing currents. When confronted by new realities, if left adrift or simply ignored, the policy can leave its affected stakeholders in a state of dysfunction, where its purpose, its operations and its means are no longer capable of generating positive outcomes.

In the case of the NSBA, some fundamental elements are weakening its provision of a sustainable and dynamic mechanism for LSBs. In some ways, the NSBA is unintentionally leading LSBs off course, as it constrains residents in their ability to effectively manage and administer the services they are mandated to provide.

The more significant flaws that are explored in this paper include the need for LSBs to undertake long-term planning, the issue of a gradually increased workload for volunteers sitting on the boards without adequate support and benefits, some obvious conflicts between the NSBA and other government policies, and the implementation challenges resulting from the LSB Program's compatibility issues with other programs. 


\section{A need for long-term planning}

The NSBA only authorizes one-year terms of office for all Board members. When originally written, the understanding of an LSB was that of a legally constituted self-help body of elected members, not unlike commonly-known not-for-profit organizations. One-year terms of office made sense since the Boards only needed to coordinate contractual agreements for the delivery of services. Long-term planning did not seem necessary.

In 2007, a LSB with the powers of Water and Sewage does not have any choice but to undertake long-term planning. It is obligated to have in place voluminous operating manuals for each of its treatment plants. It is also required to maintain a plethora of reports and plans, including annual compliance reports, emergency protocols, contingency plans, asset management plans, and now, with the upcoming Clean Water Act to be in force at some point in 2007, drinking water source protection plans. $^{3}$

Even for LSBs without the powers of Water and Sewage, long-term planning is becoming more warranted, as their financial burden increases as a result of new rules, regulations and responsibilities imposed on LSBs by other jurisdictions.

For example, under the NSBA, LSBs are required to obtain audited financial statements annually. With the expansion of rules per cent under the Generally Accepted Accounting Principles, audit costs for LSBs have increased over 28 between 2001 and 2004.

Another example is the over-sized coverage provided to LSBs by insurance companies, because the only insurance policy available to LSBs is the one formulated for municipalities. This issue has translated into astronomical insurance costs for LSBs, with a recorded 93 per cent increase between 2001 and 2004 .

The following spreadsheet was prepared by MNDM to assess the increased audit and insurance costs from 2001 to 2004: the data was obtained through a cost survey among 40 LSBs, based on their annual audited financial statements.

\begin{tabular}{|l|l|l|l|l|l|l|l|}
\hline \multicolumn{2}{|l|}{ Local Service Boards (Audit and Insurance Survey) } \\
& $\begin{array}{l}\text { \% } \\
\text { Chan }\end{array}$ & & $\begin{array}{l}\text { \% } \\
\text { Chan }\end{array}$ & & $\begin{array}{l}\text { \% } \\
\text { Chan }\end{array}$ & & \\
& ge & Actual & ge & Actual & ge & Actual & Actual \\
& $\mathbf{0 3 - 0 4}$ & $\mathbf{2 0 0 4}$ & $\mathbf{0 2 - 0 3}$ & $\mathbf{2 0 0 3}$ & $\mathbf{0 1 - 0 2}$ & $\mathbf{2 0 0 2}$ & $\mathbf{2 0 0 1}$ \\
\hline Total Actual Audit & 20.25 & $\$ 440,4$ & 13.31 & $\$ 366,2$ & 29.51 & $\$ 323,2$ & $\$ 249,5$ \\
and Insurance Costs & $\%$ & 47.00 & $\%$ & 63.90 & $\%$ & 47.68 & 95.05
\end{tabular}

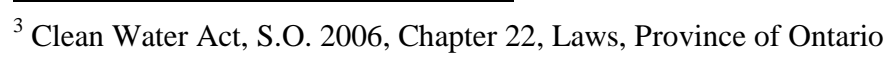




\begin{tabular}{|l|l|l|l|l|l|l|l|}
\hline $\begin{array}{l}\text { \% change 2001 to } \\
2004\end{array}$ & $\begin{array}{l}76.46 \\
\%\end{array}$ & & & & & & \\
\hline $\begin{array}{l}\text { Total Audit Costs } \\
(\% \text { change01-04) }\end{array}$ & $\begin{array}{l}28.42 \\
\%\end{array}$ & $\begin{array}{l}\$ 82,69 \\
5.00\end{array}$ & & $\begin{array}{l}\$ 74,93 \\
7.13\end{array}$ & & $\begin{array}{l}\$ 88,00 \\
0.19\end{array}$ & $\begin{array}{l}\$ 64,39 \\
4.58\end{array}$ \\
\hline Total Insurance & & & & & & & \\
Costs (\%change 01- & 93.17 & $\$ 357,7$ & & $\begin{array}{l}\$ 291,3 \\
26.77\end{array}$ & & $\begin{array}{l}\$ 235,2 \\
47.49\end{array}$ & $\begin{array}{l}\$ 185,2 \\
00.47\end{array}$ \\
$04)$ & $\%$ & 52.00 & & 26.77 \\
\hline
\end{tabular}

Increased workload without the needed support and benefits

Another point of contention for LSBs is the section of the NSBA that prohibits Board members from receiving remuneration for the performance of their duties. As a consequence, it has become increasingly difficult for LSBs to attract new Board members. The significant workload imposed on them in the administration of services has become unattractive for most. The steep learning curve is such that many community members are discouraged from accepting a volunteer position on the Boards.

The intricacy of issues and expansion of the number of players involved complicates the management task for the volunteer Board members. To substantiate this, the following is a list of the more common legislations that impact on LSBs:

$\square$ Municipal Act, Ministry of Municipal Affairs and Housing

$\checkmark$ Freedom of Information and Protection of Privacy Act, Privacy Commissioner

$\square$ Fire Protection and Prevention Act, Ministry of the Solicitor General and Correctional Services

$\square$ Provincial Land Tax Act, Ministry of Finance

$\checkmark$ Public Libraries Act, Ministry of Citizenship and Culture

$\square$ Public Lands Act, Ministry of Natural Resources

$\square$ Safe Drinking Water Act, Ministry of the Environment

$\square$ Ontario Water Resources Act, Ministry of the Environment

$\square$ Environmental Protection Act, Ministry of the Environment

$\square$ Clean Water Act (forthcoming), Ministry of the Environment

The NSBA versus other policies

The NSBA cannot be administered in a vacuum. A horizontal governance model is imposing itself on all government ministries, agencies and institutions, where a collaborative and coordinated approach involves all those concerned, "moving from a technocratic exercise to that of a participatory democracy" (Peach, 2007). A policy that is developed without the input and participation of all stakeholders, is more likely to experience conflicts in its implementation. 
Leslie A. Pal supports this principle in the following: "Horizontal consistency, or consistency across policy fields not just within them, is an expectation that what governments do in one field will not contradict what they do in another" (Pal, 2001, p12).

There are apparent conflicts between the NSBA and policies or regulations from other ministries. These have created issues for LSBs in their efforts to comply with the NSBA.

For instance, the Ontario Fire Marshall (OFM) enters into agreements establishing and governing fire departments to provide fire prevention and fire protection services in territories without municipal organization. The section of the agreement that pertains to the area serviced by the fire department includes a provision allowing the fire department to provide services outside of its set boundaries at the discretion of the Fire Chief.

The NSBA only authorizes the LSB to provide the designated services within its boundaries. When a fire department determines to provide fire protection outside of the LSB area, it does so to the detriment of the LSB's mandate under the NSBA.

This presents an opportunity for the MNDM or the OFM to tackle this issue at the policy level collaboratively. To date, the only course of action undertaken has been by a few individual LSBs to have their contracts with the OFM amended to comply with the NSBA. They have ensured that the fire department area corresponds with that of the LSB, and that the fire department is restricted from providing fire protection outside of the designated area.

The Ministry of Municipal Affairs and Housing (MMAH) also has overlapping policies that affect LSBs. The most recent example is the introduction of procurement guidelines for municipalities and local boards. Section 271 of the Municipal Act states that: "Before January 1, 2005, a municipality and a local board shall adopt policies with respect to its procurement of goods and services". 4

Interestingly, the MNDM proceeded to administer this new requirement to LSBs, even though the NSBA states: "A Board is not a municipality or a local board for the purposes of any Act". It $^{\circ}$ was determined that LSBs are subject to certain provisions of the Municipal Act as they relate to the delivery of services.

However, the Municipal Act states that the procurement guidelines apply to local boards under the authority of municipalities. In fact, the Municipal Act clearly defines local boards as: "a municipal service board, transportation commission, public library board, board of health, police services board, planning board, or any other board, commission, committee, body or local

\footnotetext{
${ }^{4}$ Municipal Act, S.O. 2001, Chapter 25, Laws, Province of Ontario (Section 271 (1))

${ }^{5}$ Northern Services Boards Act, R.S.O. 1990, c. L. 28, Laws, Province of Ontario (Section 6 (2))
} 
authority established or exercising any power under any Act with respect to the affairs or purposes of one or more municipalities". 6

This last example points to inconsistencies that may exist in the treatment and definition of LSBs. The danger lies in the lack of clearly defined parameters of LSBs, and an ambiguous understanding of their purpose, character and capacities. In the case of the procurement guidelines, the regulation may not be easily integrated at the LSB level, considering the volunteer nature of its Board, and the absence of paid staff to fulfill the ensuing administrative tasks.

By making such a determination, the MNDM opens the way for some in other jurisdictions to infer that LSBs are not unlike municipalities although they may be defined differently. The danger in this is that LSBs may end up being excessively burdened with regulations and guidelines without having in place either the means or the structure to comply with them in an appropriately manageable and sustainable way.

\section{The NSBA's power of roads: Impossible to implement}

Another issue arises when central agencies or ministries invent models in isolation from line department input, resulting in the creation of utopian models that cannot be implemented. This has become evident with the insertion of the power of Roads to the list of services that LSBs are authorized to deliver.

Added to the NSBA in 1999, which flowed from the Local Services Realignment reforms, the power of Roads was intended to achieve costs savings and administrative efficiencies by consolidating Local Roads Boards (LRB) and 50/50 Agreements with Local Services Boards. This would eliminate the duplication of administrative workloads and ensure a more efficient use of resources.

Additionally, a number of LSBs have roads inside their boundaries that are not covered by LRBs or 50/50 Agreements. The new power was intended also to address this gap by providing the LSBs with the authority to assume the responsibility of maintaining these roads.

Two possible options should have been considered to ensure that funding and technical support was tied to the new power of Roads and make it viable:

1. Transfer the MTO agreements with the current LRB to the LSB and maintain the same contractual arrangements.

\footnotetext{
${ }^{6}$ Municipal Act, S.O. 2001, Chapter 25, Laws, Province of Ontario (Section 1 (1))
} 
2. Reduce the funding allocation to the LRB program and increase the LSB program's allocation. Better yet, transfer the LRB program to the MNDM.

The first option would be highly impractical since the LRB program, managed by the Ministry of Transportation (MTO), has a very different administrative and financial framework than the LSB program.

The MTO delivers the LRB program on behalf of the MNDM. The two ministries handle the administration of funding for roads in the unincorporated areas. The involvement of LRBs and 50/50 agents in the process entails providing input into the desired level of maintenance for the roads and raising their share of the associated costs through levies imposed on properties, which are in turn remitted to the MTO.

The MTO and the LRB or the 50/50 agent make the final decision on the scope of work to be done during the year, and the MTO contracts out the work according to the set budget based on up to 1:1 matching dollars with the LRB or a 50/50 cost sharing arrangement with the 50/50 agent. Bridge rehabilitation or replacement is also a component of the LRB program and is funded entirely by the MNDM.

While the power of Roads falls under the NSBA, should the agreements in place with LRBs or 50/50 agents be transferred to LSBs, the jurisdictional authority over the administration of this power would remain under the MTO. The MTO's administration of the program would need to be fundamentally changed if it were to be compatible with the way the LSB program is funded.

Essentially, the LSB program funding is based on the LSBs' eligible expenses. Since costs incurred for the power of Roads would be managed by the MTO, and would not be processed through the LSB's operating budget, these expenses would not be taken into account in the calculation of the MNDM funding.

Another concern with the first option is the fact that many LRBs include roads that extend outside of LSB boundaries. Given that the NSBA prohibits the LSBs from delivering services outside of their delineated areas, transferring responsibilities from a LRB to a LSB would, in most cases, result in compliance issues with the Act.

With the second option, it may seem logical that, as the responsibility over local roads is transferred from the LRB or the 50/50 agent to the LSB, the associated dollars would move from the MTO to the MNDM. The problem stems from the administration of the LRB program. As it stands, the program is administered by the MTO, and with this responsibility are tied human and financial resources. 
It may be too simplistic to suggest that this dilemma could be solved by transferring the LRB program from the MTO to the MNDM. On the surface, one could deduct that giving MNDM sole responsibility over the LSB's power of Roads would result in cost savings and improved administrative efficiencies. The difficulty resides in the fact that there are presently only 46 LSBs in Northern Ontario, against a backdrop of 191 LRBs and 119 50/50 Agreements. Additionally, not necessarily all of the 46 LSBs would be interested in taking over the power of Roads. This would be like painting an entire neighbourhood green to match a few newly renovated homes.

The LSB power of Roads also is negated by the absence of funding to support this power. Since the LSB funding has been frozen since 1997-98, funding allocations for a LSB will not increase with the addition of the power of Roads. Consequently, no LSB has requested the new power since its inclusion into the NSBA.

\section{A raft with leaks: Funding and program issues}

Once legislation is in place, the government ministry or agency assigned with implementing the policies will develop the administrative framework and put in place programs that embrace the intended goals and established procedures. This is where theory meets reality. The outputs will inevitably impact on the outcome.

The LSB program was established as the framework to guide and support the communities that adopted the LSB concept. The success level of LSBs is relative to the program's flexibility and responsiveness to local needs. Unfortunately, the program has had difficulties adjusting itself to the changing environment. Furthermore, some of the more recent turbulence experienced by LSBs may have been somewhat exacerbated by decisions made at the program administration level.

Some of the current issues that plague LSBs are resulting from a series of administrative decisions made by MNDM over the past 10 years. Whether through determined actions or inactions to adjust the NSBA and the associate LSB Program, the most noteworthy decisions include the imposed funding cuts to the programs, the limits imposed on LSBs in their ability to generate revenues, the gap in financial support to upgrade LSB infrastructures, and a void of capacity building regimes for LSBs and for those working with them.

\section{Cutting corners on provincial funding}

In 1997-1998, the provincial government announced a 14.8 per cent cut to the Community Reinvestment Fund, a Ministry of Municipal Affairs and Housing funding program to assist municipalities with the delivery of programs and services. This funding cut was part of the 
province's cost reduction measures that accompanied the Local Services Realignment process. The MNDM applied the same 14.8 per cent cut to the LSB program funding. The cut was followed by another 8.6 per cent reduction in funding to LSBs in 1999-2000. Subsequently, the LSB funding was frozen at pre-1997 levels, eliminating the 1:1 funding formula that had been in place since the program's inception in 1979.

In 2004, the MNDM contribution toward the LSB eligible expenses averaged 25.1 per cent. Since any increase in expenses must be solely absorbed by the community, the MNDM's proportional share continues to decrease annually. In recent years, the abrupt rise in insurance and audit costs, along with escalating energy costs, from electricity to heating oil and propane, amplified the strain on the LSBs, which are gradually more limited in their capacity to raise funds to meet their financial obligations.

\section{The NSBA's revenue generation options: An incapacitating formula}

A LSB has three means of generating revenues to cover its portion of the operating expenses. It can hold fundraisers, include a rate to be collected through the Provincial Land Tax billing, or establish a service charge system to be administered locally. As LSB budgets swell, many find themselves in a precarious situation where the only available method of generating new revenues is through fundraising activities.

This leaning can seriously impair the LSB's viability, as residents shift an inordinate portion of the financial burden on the volunteer Board rather than assuming an equitable share of the LSB's finances by voting against rate increases.

The NSBA contributes to this imbalance by prohibiting the LSBs from adding rates unless approved by a majority vote of the inhabitants present and voting at a meeting called for that purpose. Originally, this clause may have been intended to encourage a participatory approach and ensure accountability. In the present context, it contributes to weakening the LSB's sustainability by facilitating an unhealthy repositioning of the financial responsibilities, which gradually weigh more heavily on the volunteer Board than on the community as a whole.

\section{LSB infrastructure woes: Less than too little funding}

Even as the LSB's operating expenses inflate, the state of its infrastructure deteriorates. LSBs are not always eligible under infrastructure funding programs because they are not municipalities. This was the case with Infrastructure Ontario's Rural Infrastructure Investment Initiative in 2007.

Other programs require LSBs to compete against municipalities for infrastructure dollars, such as 
the Canada-Ontario Municipal Rural Infrastructure Fund. LSBs tend to be disadvantaged through such a process, challenged to submit proposals that best present their case against grant applications prepared professionally for or by municipalities.

LSBs are doubly disadvantaged by the fact that the NSBA does not give them the flexibility to increase rates at their leisure without the consent of the community members. Even though rate increases may be necessary to build a proper working reserve for ongoing maintenance or periodic infrastructure upgrades, leaving the final say in the hands of homeowners too often results in rejection, thus perpetuating the LSBs inability to afford necessary, even at times mandatory repairs.

Furthermore, LSBs are not authorized to incur debts that go beyond the current fiscal year. Financing options like the Ontario Strategic Infrastructure Financing Authority are therefore unavailable to LSBs. They are in all likelihood condemned to undertake inexorable and laborious fundraising activities to raise special funds to cover the community's share of any infrastructure project.

As a consequence, whenever funding programs are made available, LSBs are only in a position to bring in piece-meal repairs because they do not have the financial resources to undertake fullscale projects. Once a funding program has rolled through, LSBs will have completed only a portion of the needed repairs, perpetuating its infrastructure's descent into disrepair.

\section{Absence of capacity building}

Another element that negatively affects the ability of LSBs to deliver services in an effective and efficient manner is a capacity deficit caused by a lack of learning and training opportunities for Board members. The burgeoning of legislation that affects LSBs is not matched by an increase in knowledge transfer. Board members are left on their own to steer against the flow of onerous requirements, laws and regulations.

The last formal learning opportunity for Board members was a LSB conference organized by the MNDM in March of 2000. No other training exercise or workshop has been held since, other than impromptu information sessions on single topics that would take place generally during regularly scheduled LSB meetings.

Since there is no umbrella organization that represents LSBs, comparable to the Northern Ontario Municipal Association or the Federation of Northern Ontario Municipalities, a concerted approach to training is non-existent. The isolation deprives LSBs of opportunities to share best practices, to discuss issues and propose solutions, to develop support systems, and to challenge one another to excel. 


\section{Up the creek without a paddle: Procedures with limited force and means}

A program must receive continuous and measured attention from its governing body if it is to generate good results and best serve its purpose. Undeniably, when human dynamics are involved, boundaries are tested, needs are in constant fluctuation, and the rules of engagement steadily evolve. It becomes incumbent upon all those involved to adhere to a performance management regime that clearly defines expectations and promotes an observance of roles and responsibilities.

\section{A need for performance management}

Some of the LSB program's issues reside in the MNDM's limited capacity to implement a performance management regime internally and in its dealings with LSBs. This is mainly due to workload and to personnel restrictions that preclude the ministry from offering the support, training and monitoring at the levels required.

Because of the high turnover of volunteers sitting on Boards, and because MNDM staff are unable to provide regular training to Board members, some LSBs have strayed from the prescriptions of the NSBA. Whether out of negligence or from inexperience, LSBs have on occasion delivered services outside of their boundaries, incurred long-term debts without the MNDM Minister's authorization, exercised powers without requesting the Minister's order granting such powers, or gotten involved in activities outside of the intended purpose of an LSB, such as economic development projects.

More importantly, LSBs may also at times be in non-compliance with other Acts and regulations that have jurisdiction over them. Even though the NSBA gives the LSB the flexibility to establish its own rules and procedures for transacting the business of the Board, it is not exempt from following taxation laws, procurement guidelines, generally accepted accounting principles, conflict of interest rules, or protection of privacy, to name but a few.

It is the role of the MNDM staff to guide and advise the LSBs through their processes. They may at times be ill-equipped to provide the needed information and support, especially when it pertains to matters under other jurisdictions. Not unlike the LSB volunteers, the MNDM staff have not received the level of training relative to the influx of new legislation, programs, rules and regulations affecting LSBs in recent years.

Many LSBs also have difficulty abiding by the LSB program funding guidelines. The MNDM has the responsibility to administer the LSB funding program with transparency and accountability, but does not have an established mechanism to reprove LSBs that drift away from the suitable execution of their responsibilities. 
Even though significant improvements have been made in recent years by the MNDM to frame the funding and reporting process for LSBs, many are still delinquent in providing the required support documentation, in properly filling out the budget estimates used with their funding request, and in observing the set deadlines for submitting funding requests.

Employees assigned a specific task can become uneasy in their role if they feel inadequately prepared or if they haven't received sufficient training. The MNDM staff training on LSB administration and monitoring has decreased progressively over the years. Employees are becoming less adept at their duties related to the LSB program and therefore less equipped to provide the needed support to LSBs. The indirect result of this is an inconsistent level of efficiency among LSBs.

In the absence of a well-established performance management regime, both the MNDM and LSBs lose interest and fail to consider essential elements that ensure effectiveness and accountability. Complacency and, in some cases, disorder sets in, where the partners consider each other as annoyances, and where compliance on one end and support on the other end are offered reluctantly, more out of obligation than out of a shared sense of purpose. The perceived lack of attention by the MNDM to their needs and issues encourage LSB members to become cynical and uncooperative. If sustained, this condition will predictably lead to a failed partnership.

\section{From a drifting raft to a taut ship}

Having a balanced approach in the administration of programs can be particularly demanding, especially when fiscal constraints impinge upon the governing body's room to manoeuvre. Coordination then becomes paramount to facilitate proficient management with touchstones and a shared vision.

The MNDM will first need to engage in a deliberative process, allocating time and resources, to redress the situation by acknowledging the issues, encouraging collaboration and focusing on the rewards. This will not happen if there is no appetite for change, even though inaction may plunge the LSB program into dangerous waters. Moreover, crisis should never be the motivating factor for change.

A mandate that requires implementation and monitoring in perpetuity can only be fulfilled if an appropriate level of funding is in place to assist the stakeholders in meeting their obligations. This said, if the MNDM has no other means at its disposal to invest in its LSB program, it is incumbent upon it to put in place the necessary arrangements and framework to support the community's ability to raise adequate funds for the administration and delivery of services. This would require legislative change, which is an unappealingly lengthy and cumbersome process. 


\section{Addressing the LSB financial crunch}

An easier route would be to be proactive in providing solutions that will help alleviate the financial strain on LSBs. A perfect example is the issue of escalating insurance costs. As stated earlier in this document, the only insurance coverage available to LSBs is through policies specifically formulated for municipalities. This has resulted in over-sized coverage for the LSB needs, at a cost that has become unaffordable to them.

An insurance broker with a number of LSB clients has been working for two years with an insurance company to develop a new program specifically formulated to mesh with the mandate, assets and activities of LSBs. The estimated cost savings to LSBs would be in the range of 20 to 35 per cent. As in any other similar program, the number of participating LSBs would determine the level of savings available to them.

In order to ensure a successful roll-out of the new insurance policy, a coordinated and targeted marketing strategy would need to be undertaken by the private sector business. Ensuring that all of the LSBs are made aware of the new policy would be possible only with the help of the MNDM in accessing LSB mailing information.

Any concerns over the protection of privacy would be easily addressed by informing the LSBs of the MNDM's intentions, and by obtaining their consent in providing their mailing information to the insurance broker. As is common in the public sector, there may be concerns over the perception that the MNDM, in doing so, would provide unfair support to a single business in a competitive environment. This concern is easily allayed since there is no other such insurance program in existence in the province of Ontario. In this sense there is no competition to speak of.

In the event that this venture was to be coordinated or mandated by the MNDM, due process would have to be applied, including a request for proposals and a competitive process. In this specific case, the MNDM would in no way be involved in the development of the new policy; the project would be driven strictly by the private sector that saw a need, and determined to respond to it.

Another proactive response would be for the MNDM to get involved in providing solutions when opportunities present themselves. Such an opportunity surfaced in 2005 when the Federal Government began a dialogue on including LSBs in the Federal Gas Tax Revenue Program.

Original negotiations on the Federal Gas Tax Revenue Program resulted in a per capita formula being devised, which did not include Unincorporated Areas. The Ministry of Municipal Affairs 
and Housing coordinated the Province's involvement in the Federal Gas Tax Program. The Province had no role in the allocation and program decisions. The Federal Government worked directly with the municipalities through the Association of Municipalities of Ontario.

A Federal Parliamentarian enquired from the MNDM if the province would oppose the use of the Gas Tax Revenue Fund for unincorporated areas, if the MNDM would be willing to administer the program on behalf of the Unincorporated Areas, and how the funds would flow to the unincorporated areas.

Funding for Local Service Boards and Local Roads Boards was set at \$5.8 million. The per capita allocation was calculated based on 2001 Census data. LSBs account for approximately 72 per cent of the population in unincorporated areas and therefore, could potentially qualify for $\$ 4.1$ million based on a per capita of $\$ 162.39$.

Unlike the Provincial Gas Tax Program, which is only earmarked for transit in municipalities, the proposed Federal Program allowed for greater flexibility. Other projects and activities could potentially be eligible, should sustainable infrastructure be considered eligible for funding.

Under the Federal Guidelines, roads and bridges would be eligible. Although the Power of Roads is an eligible Power for LSBs to apply for, currently there are no LSBs with the power of Roads.

Since many Local Roads Boards exist in the same areas as LSBs, it was apparently more practical to suggest that consideration be given to allow these bodies access to funding under the Gas Tax Revenue Program rather than LSBs.

There have been no indications since from the Federal Government whether it has developed the administrative approach for the flowing of funds to the unincorporated areas, nor has a decision been made on whether funding would be through an allocation or an application process.

In 2007, the province's municipalities have already received two payments from the Gas Tax Revenue Program, while LSBs wait patiently for funding that may never materialize.

In this instance, the Province, and the MNDM in particular, could have played a more active role in developing a workable approach for the administration and flowing of funds allowing LSBs to benefit from this Federal subsidy. Although a fairly minimal workload would have been assumed by the Province, it would have participated in the efforts to help alleviate the financial scourge experienced by LSBs. 


\section{Fixing the infrastructure deficit: Some simple policy solutions}

The issue of infrastructure deficit in the LSBs can be tackled from one angle with relative ease. Short of actually providing funding, the MNDM could ensure that LSBs are included in all provincial infrastructure funding programs.

Those who argue that LSBs are not municipalities and should not have equal access to funding programs should be reminded that LSBs are subject to the same regulatory frameworks as municipalities, especially with regards to water and waste water systems.

Another solution that requires little administrative effort is to keep the LSBs from being lumped into the same competitive process as municipalities. LSBs are run by a Board of volunteers, with no employees other than a Secretary who may receive a small, and in many cases, negligible honorarium. Unlike municipalities, LSBs do not have professional staff to prepare their grant applications, nor can they afford consultants to build proposals with an acquired competitive edge.

Where funding is determined through a competitive process, a separate set of criteria for LSBs could be established. Alternatively, when a points system is used, valuation and measurements can be configured differently for LSBs.

Finally, the challenge for LSBs to raise adequate funds to cover their share of infrastructure project costs must be given added attention. LSBs have received special consideration in the recent past, with programs such as the Drinking Water Protection program under the Northern Ontario Heritage Fund (NOHFC), where they were given supplementary funding to help reduce their portion of project costs.

The MNDM could advocate on behalf of LSBs to ensure that they are given proper consideration whenever a funding program is set to be rolled out. Had this been the case in 2007, the Public Infrastructure Renewal's Rural Infrastructure Investment Initiative could possibly have included LSBs as eligible applicants.

\section{Building capacity}

Providing training and imparting knowledge and skills in areas where responsibilities are assigned is a fundamental requirement to ensure efficient implementation. Competence can not be developed in a void. It needs nourishment, attention and support. The recompense for the needed investments in building capacity is an appropriate and effective management and performance of duties. 
The MNDM stands to gain by increasing capacity building for LSB volunteers. Support through the provision of training will help build a more productive working relationship between the LSBs and the MNDM staff. LSBs will also benefit by increasing their level of proficiency in the administration of their powers, thus improving their independence and adding stability to their operations.

Building capacity can be achieved by three practical means:

1. On-going support through yearly training and updates to the Northern Services Boards Act and the Local Services Board Program: This could take place following the LSB's election meetings, held prior to the new fiscal year starting October $1^{\text {st }}$. A session following the election meeting could serve as an ideal training opportunity for the newly elected board members, serving as a launching exercise for the upcoming year, preparing them to fulfill the requirements and responsibilities assigned to them.

2. Quinquennial Local Services Boards Conference: Similar to the last conference held in Sault Ste. Marie in 2000, the MNDM could systematically hold a conference for Board members and secretaries where thematic training would be provided. As well as being an ideal networking opportunity for LSBs, these conferences would serve to reinforce the capacity of volunteers in the areas of meeting management, LSB administration, relevant provincial policies, financial planning, volunteer recruitment, and dealing with service delivery issues.

3. The establishment of an umbrella organization for networking and peer support: Building capacity can best be achieved through informal and spontaneous exchanges between LSB representatives, as experience and best practices can be shared without expense or coordination efforts. An umbrella organization similar to the Federation of Northern Ontario Municipalities (FONOM) could also serve as a forum for LSBs to clarify challenges and issues they experience, and collectively articulate their needs and enquiries with provincial and federal governments. The MNDM could help facilitate the establishment of this umbrella organization, given that it alone has access to all of the LSB contact information. This organization could be created during a quinquennial conference organized by the MNDM.

All of these proposed solutions to promote capacity building in LSBs require some level of commitment and engagement. As an analogy, it is not enough to give people the freedom to exercise their rights without providing them a proper understanding of their responsibilities that accompany these rights, and without educating them on the consequences of their choices.

In the case of LSBs, is it not fitting and sensible to complement the NSBA with training and 
support? This would ensure that those the Act is intended to assist are provided with adequate and finely honed tools so they can meet the obligations and responsibilities tied to the powers they are authorized to exercise.

\section{... And the ship sets sail}

"Ontarians in rural and northern communities face significant challenges that are threatening their sustainability. Provincial policies that address these special challenges will aim at helping build capacity and ensuring that these communities continue to be an integral part of the provincial landscape."7

The NSBA, even with its shortcomings, remains an essential tool for communities in the unorganized areas of Northern Ontario. Without the LSB program, citizens would not have at their disposal a mechanism that supports them in the delivery of basic community services.

While legislative change is not likely to take place in the near future, investing more time and resources toward improving the conditions under which LSBs operate should be given serious attention. Fairly simple steps can be taken to help build capacity, alleviate the financial strain on LSBs, and improve the MNDM's efficiencies in servicing those communities.

These investments can be achieved with relatively limited effort and means. Although up to now the political appetite for playing a more proactive role has been somewhat meager, a crisis in a single community that attracts enough attention to the plight of LSBs may eventually serve as the needed catalyst for change.

The hands-off approach by the Province with regards to LSBs works when the waters are calm. This detachment can no longer be practical when the LSBs find themselves in stormy waters, especially when this situation is in large part due to the conditions the Province imposes on them through the very Act that facilitated their establishment. The risk in this approach is that it can eventually be perceived as negligence.

The question remains: will the ship inevitably set sail only to find itself engulfed in a perfect storm? Or will our political leaders, civil servants, and volunteers involved with LSBs have the initiative and creativity to endeavor collaboratively to strengthen LSBs and ensure their sustainability?

"The pessimist complains about the wind.

The optimist expects it to change.

The leader adjusts the sails."

\footnotetext{
${ }^{7}$ AMO's Rural-Northern Plan Discussion Paper, Association of Municipalities of Ontario, February 2007, page 17
} 
William Arthur Ward

"I can't change the direction of the wind, but I can adjust my sails to always reach my destination." Jimmy Dean

\section{Author Biography}

Denis Rochon is the Northern Development Officer for the Ontario Ministry of Northern Development and Mines'. Working out of the Ministry's Chapleau Office for the past five years, he plays an active role in economic development of the area by assisting communities with their efforts in bringing about economic renewal through strategic development and investment attraction. He has been involved in economic and community development since 1998 in a variety of functions, such as General Manager of the Centre Culturel Louis-Hémon de Chapleau inc., Director of an arts development initiative The Quatrain Project, Interim-GM of the adult literacy centre FormationPLUS, and Coordinator of the Chapleau Nature Festival. During that period, he was also involved in the private sector as owner of a family entertainment centre, The

Game Zone, in 1996-1998, investor in the commodities and financial markets in 1998-2002, and owner of a weekly community newspaper, The Chapleau Express, in 2002-2004.

\section{References}

Association of Municipalities of Ontario (1999). Local Services Realignment: A User's Guide. Municipal Act, S.O. 2001, Chapter 25, Laws, Province of Ontario.

Clean Water Act, S.O. 2006, Chapter 22, Laws, Province of Ontario

C. Leith, Environmental Officer, Ministry of the Environment, personal communication, February 2007).

C. Jensen, Local Services Boards Program Coordinator, Ministry of Northern Development and Mines, personal communication, February 2007).

Dean, Jimmy. ThinkExist.com. Retrieved from http://thinkexist.com/quotation/

Totten Sims Hubicki Associates. (2007, July 7). Foleyet water treatment plant upgrades:Technical memorandum, Totten Sims Hubicki Associates.

Jensen, Cathy. (2000, January 13). Discussion paper on the availability of statistical information 
for the unorganized area of Northern Ontario.

Local Roads Boards Act, R.S.O. 1990, Chapter L. 27, Laws, Province of Ontario

Local Services Board Act, R.S.O. 1980, c. 252, L. 28, Laws, Province of Ontario

Northern Services Boards Act, R.S.O. 1990, c. L. 28, Ontario Laws, Province of Ontario

Statistics Canada 2001 Census. Retrieved from

http://www12.statcan.ca/english/census01/home/Index.cfm.

Ontario Ministry of Municipal Affairs and Housing. Provincial-Municipal Fiscal and Service Delivery Review. Retrieved from http://www.mah.gov.on.ca/userfiles/HTML/nts_1_28334_1.html,

Pal, Leslie A. (2007). AMO's Rural-Northern Plan Discussion Paper: Beyond Policy Analysis: Public Issue Management in Turbulent Times. Association of Municipalities of Ontario (2nd ed.).

Peach, Ian. (2007). Designing a Model for Horizontal Policy-Making. Saskatchewan Institute of Public Policy.

(R. Le Clerc, Local Services Boards Program Coordinator, Ministry of Northern Development and Mines, personal communication, March 2007).

(R. Bustard, Policy Advisor, Corporate Policy Secretariat, Deputy Minister's Office, Ministry of Northern Development and Mines, personal communication, March 2007).

Statistics Canada. (2001). 2001 Census. Government of Canada.

Totten Sims Hubicki Associates. (2005, July 7). Foleyet Water Treatment Plant Upgrades: Technical Memorandum.

Ward, William Arthur. ThinkExist.com. Retrieved from http://thinkexist.com/quotation/

Webster's New Collegiate Dictionary, (1997). G. \& C. Merriam Co. 